\title{
REVIEW
}

\section{The Pathological Relevance of Increased Endothelial Glycocalyx Permeability}

\author{
Matthew J. Butler, Colin J. Down, Rebecca R. Foster, and Simon C. Satchell
}

From Bristol Renal, Translational Health Sciences, Bristol Medical School, University of Bristol, Bristol, United Kingdom

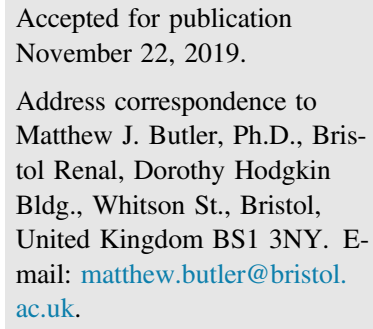

\begin{abstract}
The endothelial glycocalyx is a vital regulator of vascular permeability. Damage to this delicate layer can result in increased protein and water transit. The clinical importance of albuminuria as a predictor of kidney disease progression and vascular disease has driven research in this area. This review outlines how research to date has attempted to measure the contribution of the endothelial glycocalyx to vessel wall permeability. We discuss the evidence for the role of the endothelial glycocalyx in regulating permeability in discrete areas of the vasculature and highlight the inherent limitations of the data that have been produced to date. In particular, this review emphasizes the difficulties in interpreting urinary albumin levels in early disease models. In addition, the research that supports the view that glycocalyx damage is a key pathologic step in a diverse array of clinical conditions, including diabetic complications, sepsis, preeclampsia, and atherosclerosis, is summarized. Finally, novel methods are discussed, including an ex vivo glomerular permeability assay that enhances the understanding of permeability changes in disease. (Am J Pathol 2020, 190: 742-751; https://doi.org/10.1016/j.ajpath.2019.11.015)
\end{abstract}

Water and solute exchange across the walls of the microcirculation are dynamic processes that are fundamental to tissue homeostasis. The net rates of exchange are regulated by alterations in systemic blood pressure (hydrostatic pressure), vessel density and size (surface area), flow rate, concentration gradients, and the intrinsic permeability properties of the vessel wall. The basic structure of the capillary wall is conserved throughout the body, consisting of an endothelial cell monolayer, basement membrane, and supporting cells. However, a high level of specialization occurs within discrete areas of the vasculature, optimizing the structure for the individual demands placed on it. The endothelial glycocalyx layer found on the luminal surface of all endothelial cells contributes to the permeability barrier formed by the vessel wall. ${ }^{1,2}$ Glycocalyx literally translates from the Greek for sugar coat (glykys means sweet and kalyx means husk). This adherent structure includes proteoglycans, glycoproteins, and glycolipids (Figure 1). ${ }^{1,3-5}$ Proteoglycans consist of core proteins (eg, syndecans and glypicans) with covalently bound glycosaminoglycan side chains [eg, heparan sulfate (HS) and chondroitin sulfate]. The glycocalyx is not uniform across its depth. ${ }^{6}$ The 2-layer fiber matrix model suggests a dense 200- to 300-nm meshlike inner layer rich in proteoglycans covalently bound to the endothelial cell membrane and adherent glycosaminoglycans, including long chains of hyaluronan (HA), and an outer, more porous, gellike layer up to $1-\mu \mathrm{m}$ thick, including adsorbed plasma proteins. ${ }^{6,7}$ This review discusses the evidence for the importance of the endothelial glycocalyx as a regulator of endothelial and vascular permeability, while noting the inherent difficulties in studying it. The human diseases in which glycocalyx damage and associated permeability alterations appear to be key pathogenic steps are also reviewed.

\footnotetext{
Supported by NIH grant S10 OD021833 (USC Multi-Photon Microscopy Core), and Medical Research Council grant MR/M018237/1 (M.J.B.), and the National Institute for Health Research (M.J.B.).

Disclosures: M.J.B. is a National Institute for Health Research-funded clinical lecturer in renal medicine.

This article is part of a review series on glycocalyx in human disease.
} 


\section{The Complexities of Studying the Endothelial Glycocalyx as a Permeability Barrier}

Endothelial cells in vitro produce a surface glycocalyx that provides an accessible model to study glycocalyx functions, including shear stress sensing ${ }^{2}$ and permeability regulation. ${ }^{4}$ However, it is much thinner than the glycocalyx seen in vivo, limiting the applicability of in vitro research. ${ }^{4,8,9}$ As a result, most studies on the permeability of the glycocalyx have been conducted in vivo.

Much research to date has focused on the glomerular endothelial glycocalyx, which may be driven by the physiologic importance of permeability in glomerular function and the clinical importance of albuminuria. Furthermore, urinary albumin creatinine ratios (uACRs) can be easily quantified to provide a measure of albumin permeability across the glomerular filtration barrier (GFB) (Figure 1). Early models of the GFB overestimated the contribution of the slit diaphragm to the restriction of albumin filtration. ${ }^{10}$ Recent models of the GFB, however, suggest that the glycocalyx represents a significant protein barrier. ${ }^{11}$ This finding concurs with accumulating experimental evidence, ${ }^{12}$ indicating that the remaining components of the GFB, including the endothelial glycocalyx, provide the major barrier to protein permeability (Figure 1). ${ }^{4,13-15}$ These estimates, combined with the increased understanding of cellular crosstalk within the GFB, should make us question assumptions about the pathogenesis of albuminuria in multiple historical models. ${ }^{16,17}$

Albuminuria is the net result of albumin passage across the GFB (influenced by permeability) and albumin reabsorption and metabolism within the renal tubules. However, despite the widespread use of uACR, there is increasing evidence in rodent models that $\mathrm{UACR}$ is not a sensitive test for changes in GFB permeability and hence not an ideal index of glycocalyx integrity. Using in vivo multiphoton microscopy in mice (Figure 2) (image provided by M.J.B.), we found that glomerular albumin leakage can be significantly increased before detectable levels of albumin appear in the urine. ${ }^{2}$ Other groups have reported similar data, demonstrating increased glomerular albumin leakage but no significant change in uACR. ${ }^{18}$ Evidence suggests that that this discrepancy is explained by tubular reabsorption of filtered albumin, resulting in a threshold effect whereby increased glomerular albumin permeability will not result in UACR increases until mechanisms of uptake and metabolism are overwhelmed. ${ }^{19}$ The role of tubular albumin uptake in humans is debated, but diseases resulting in tubular dysfunction, such as Fanconi syndrome and Dent disease result in significant albuminuria. ${ }^{20}$ Historical studies in patients with diabetes using lysine to inhibit tubular albumin reabsorption similarly indicate that tubular albumin uptake may influence uACR results. ${ }^{21}$ In summary, the clinical importance of albuminuria is now well established, but the absence of albuminuria in early rodent models of disease does not exclude increased albumin passage across the GFB.

Relatively little research has been conducted studying glycocalyx-dependent permeability changes in the systemic vasculature. In part, this lack of research is attributable to the complex methods needed to study glycocalyx-specific changes. Previous studies in mesenteric microvessels by intravital confocal microscopy have demonstrated that neuraminidase, which disrupts sialic acid residues and reduces glycocalyx depth, increases microvessel permeability. ${ }^{1}$ Work

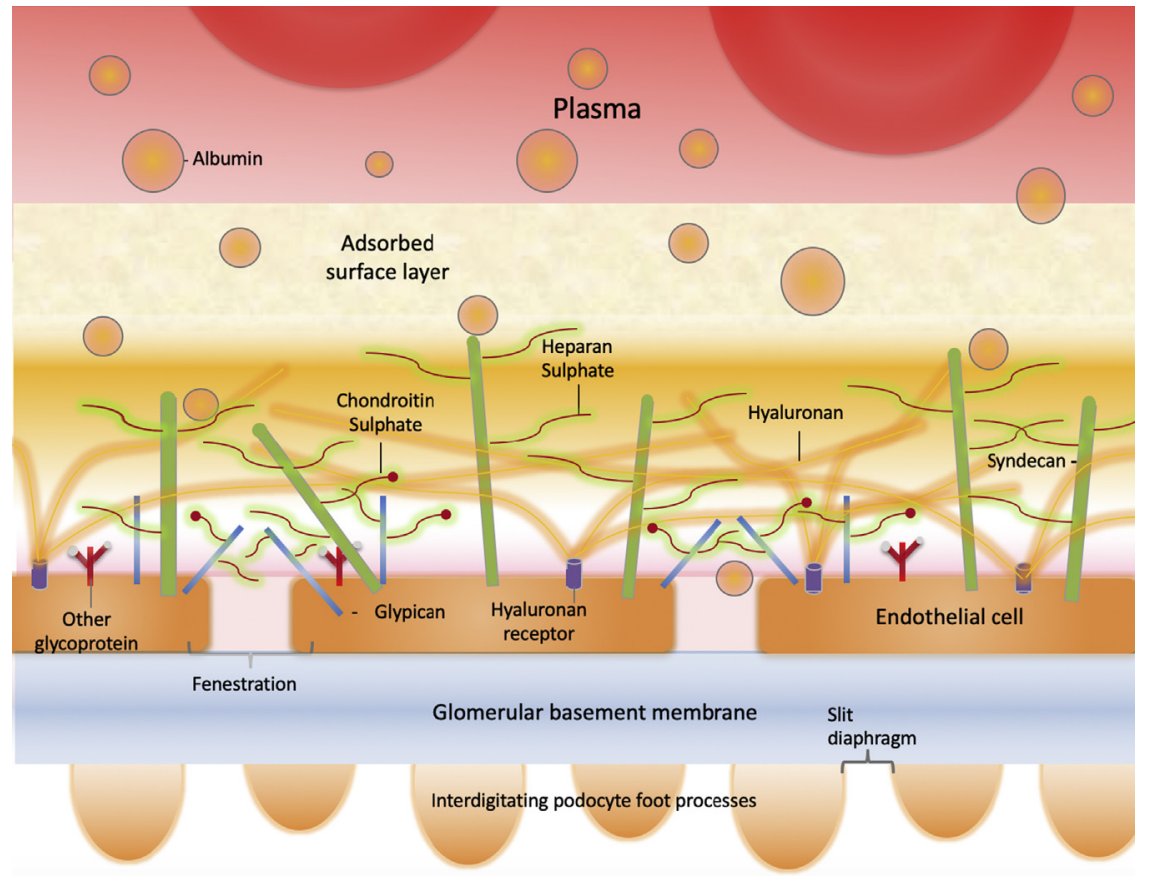

Figure 1 The glomerular filtration barrier consists of glomerular endothelial cells (GEnCs), the glomerular basement membrane, and podocytes. GEnCs possess numerous transcellular fenestrations, which permit the high hydraulic permeability necessary for filtration, and a glycocalyx, which covers the luminal surface, extending over the fenestrations. Podocytes form a second cellular layer by interdigitating their foot processes, which connect at the slit diaphragms. The glycocalyx is a complex structure that contains core proteoglycans, such as syndecans and glypicans, holding glycosaminoglycans, heparan sulfate, chondroitin sulfate, and hyaluronan to the cell surface. The glycocalyx contributes to the filtration barrier by depleting the filtrated protein concentration before it reaches the fenestrated glomerular endothelial cell surface. The generation of a zone of protein-depleted filtrate adjacent to the luminal membrane of endothelial cells (shown in pink) limits loss of macromolecules from the plasma and reduces the effective oncotic pressure across the endothelial cell body. 


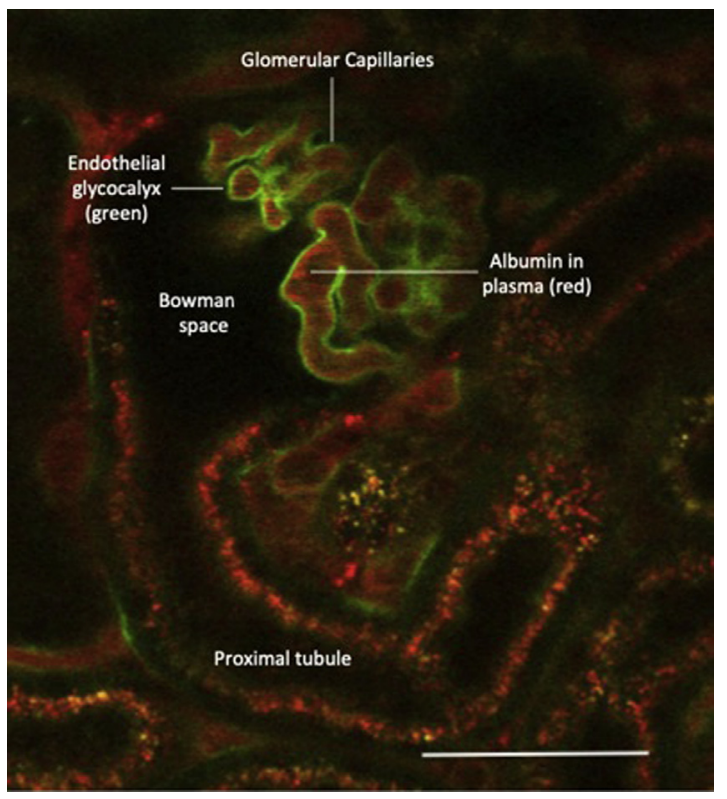

Figure 2 A live perfused mouse glomerulus under anesthesia was imaged using multiphoton microscopy. The image was taken 10 minutes after an intravenous bolus of fluorescein isothiocyanate-wheat germ agglutinin. This lectin binds to sialic acid residues within the glycocalyx (labeled green). The plasma within the capillary loops was labeled red with Alexa Flur-conjugated albumin. The dark areas within the capillary loops represent circulating blood cells. The glomerular endothelial glycocalyx is a continuous layer within the glomerular capillaries that contribute to the restriction of macromolecule and water leakage from the glomerulus into the Bowman space. Scale bar $=50 \mu \mathrm{m}$.

that compares the depth of the endothelial glycocalyx within the continuous capillaries of the systemic and pulmonary vasculature highlighted significant variability in glycocalyx depth. ${ }^{22}$ To date, little is known about whether the composition of the glycocalyx varies among these sites. It seems likely that the glycocalyx within discrete areas of the vasculature is specialized, adapting to perform the combination of tasks needed at each tissue site optimally. Variability in the glycocalyx structure means that pathologic insults may not affect all areas of the glycocalyx equally. Specialization is also seen in the endothelial monolayer itself. The double barrier concept was first introduced by Rehm et al ${ }^{23}$ and is illustrated in Figure 3. They found in guinea pig hearts that simultaneous disruption of both the cellular barrier (using ischemia or histamine) and glycocalyx damage (using heparinase) was needed to increase coronary vessel leakage. ${ }^{23}$ This work led to the hypothesis that glycocalyx damage overlying a tight cellular barrier will have minimal (direct) influence on monolayer or vessel wall permeability. In contrast, identical glycocalyx damage overlying a leaky cellular monolayer will result in rapid measurable increases in vessel permeability. When glycocalyx-dependent permeability changes within the systemic vasculature are studied, it is therefore important to consider how both glycocalyx structural adaptations and the underlying endothelial cell phenotype will influence detectable permeability changes.
To measure the contribution of the endothelial glycocalyx to vessel permeability, comparisons have generally been made after a glycocalyx insult. Enzymatic removal or genetic knockdown of a specific glycocalyx component is commonly used for this purpose. However, the method used can significantly alter the results of such studies. Rapid removal of HS, using human heparanase or bacterial heparinase III, increased albumin passage across endothelial monolayers. ${ }^{4}$ However, knockout of the HS proteoglycan syndecan 1 did not result in albuminuria in mice. ${ }^{24}$ In addition, mice that lacked endothelial $\mathrm{N}$-deacetylase and $\mathrm{N}$ sulfotransferase, a key enzyme in modifying HS chains, did not become albuminuric. ${ }^{25}$

A similar pattern of results was seen in experiments that target HA. Hyaluronidase, an enzyme that degrades HA, has a plasma half-life of approximately 3 minutes before being taken up in the liver via a mannose-dependent mechanism. ${ }^{26}$ The short plasma half-life and the relatively high molecular weight (55 to $61 \mathrm{kDa}$ ) of hyaluronidase result in a high level of glycocalyx-degrading activity with limited off-target effects. Several studies found that removing HA from the endothelial glycocalyx, using hyaluronidase, increased glomerular albumin transit 5.6-fold, a figure consistent with findings. ${ }^{27-29}$ Tamoxifen-induced endothelial-specific knockdown of HA synthase 2 (a membrane-bound HA synthesis enzyme) also resulted in significant albuminuria from 4 weeks after induction, which persisted to 12 weeks (experimental end point). ${ }^{30}$ In contrast, Dane et al ${ }^{18}$ found that 4 weeks of hyaluronidase infusion did not result in measurable albuminuria, although they found increased glomerular albumin leakage in $90 \%$ of glomeruli.

Although this work, again, highlights the fact that albuminuria is a poor measure of low-level glomerular albumin leakage, it also suggests that the differences in time scale, as well as the precise component targeted, may influence glycocalyx permeability changes. Knockdown in genetic models may have resulted in compensatory adaptations (eg, up-regulation of other glycocalyx components). In contrast, the rapid enzymatic removal of glycocalyx components may prevent adaptations from occurring before functional assessments are made..$^{25,27-29,31}$ In addition, the rapid removal of a single structural component of the glycocalyx may leave the structure as a whole vulnerable to further nonspecific destruction by the shear forces applied by the circulation. Another contrast between enzymatic removal and genetic knockdown of a glycocalyx component is the generation of circulating glycocalyx fragments. The enzymatic release of fragments is also nonspecific. Heparanase increased syndecan 1 and 4 loss from the glycocalyx structure, possibly by exposing cleavage sites for the actions of other circulating enzymes. ${ }^{32}$ The influence of active signaling fragments released after glycocalyx enzymatic degradation on vessel permeability has not been directly investigated, but they represent a potentially important pharmacologic target. ${ }^{33,34}$ 


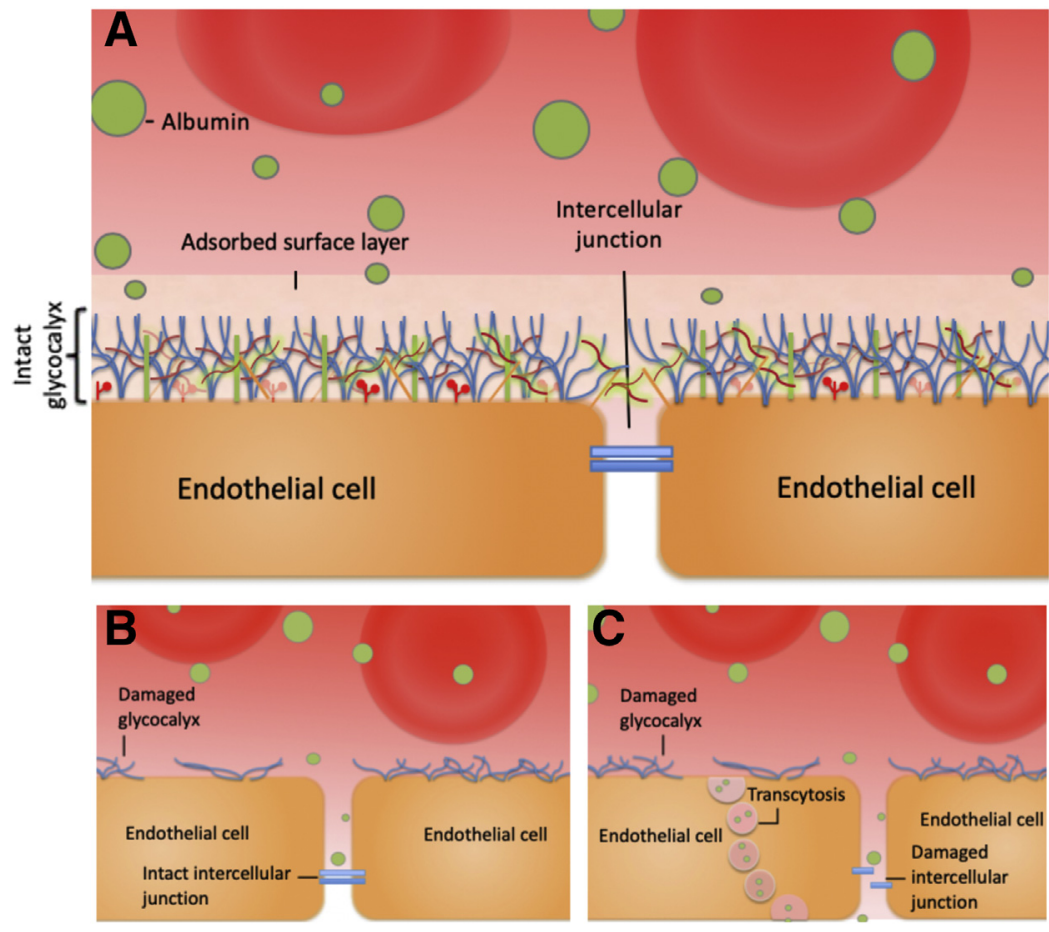

Figure 3 The double barrier concept. A: In health, both the intact glycocalyx and a tight endothelial monolayer can limit vascular wall permeability to macromolecules (including albumin). B: When damage to the endothelial barrier is limited to the glycocalyx, in areas of the vasculature where a tight cellular monolayer exists, an intact second barrier remains. This tight endothelial monolayer continues to limit macromolecule transit. In such areas, it is currently not possible to directly measure the contribution of the endothelial glycocalyx to the vessel wall permeability. C: When damage affects both the glycocalyx and the permeability of the underlying monolayer, marked increases in the vascular wall permeability will result, but again calculating the relative contribution of the glycocalyx to the vessel wall permeability is not possible. In summary, to directly measure the contribution of the glycocalyx to vessel permeability, vessels that lack a tight endothelial monolayer must be selected until new techniques are developed that can measure macromolecule concentrations in the subglycocalyx space.

In summary, when the glycocalyx is studied, careful consideration needs to be given to the chosen method and tissue. Although the glomerular endothelial glycocalyx lends itself to studying permeability, the uACR should be interpreted with caution. Measures of systemic permeability need to be considered in context. A double barrier can exist, and in the absence of specific manipulations, the relative contributions of the components are difficult to establish. With the development of more sensitive and specific methods to assess permeability, the role of individual glycocalyx components are expected to be better understood in the next decade. ${ }^{35}$

\section{The Relevance of Glycocalyx Permeability Changes in Disease}

\section{Diabetes}

There is evidence that the diabetic milieu affects the vasculature globally. Nieuwdorp et $\mathrm{al}^{36}$ measured the total glycocalyx volume by comparing the volume of distribution of erythrocytes and dextran 40 in healthy volunteers. They found that 6 hours of hyperglycemia reduced the glycocalyx volume to $50 \%$ of the baseline value. More recently, an intervention trial found that intensification of glycemic control in poorly controlled type 2 diabetic patients during 12 months (glycated hemoglobin reduction from 74 to 54 $\mathrm{mol} / \mathrm{mol}$ ) was associated with a significant increase in glycocalyx depth compared with baseline vaulues. ${ }^{37}$ Glycocalyx depth in this study was measured using side-stream dark field imaging to assess the perfused boundary region depth (a measure inversely proportional to glycocalyx thickness) on sublingual vessels, which suggests that systemic glycocalyx damage in early diabetes is at least partially reversible. ${ }^{37}$ Changes to the endothelial glycocalyx occur early in the disease course, suggesting that they could represent a valuable direct therapeutic target. ${ }^{35}$ Electron microscopy on glomerular capillaries showed that the percentage surface covered by the glycocalyx is one of the earliest detectable vascular changes in diabetes. ${ }^{35}$ Consistent with this, Targosz-Korecka et $\mathrm{al}^{38}$ used atomic force microscopy to map the glycocalyx on diabetic $\mathrm{db} / \mathrm{db}$ mouse aortas. They found that endothelial glycocalyx coverage was significantly reduced by week $11 .^{38}$ At this time point, significant reductions in the glycocalyx depth were not detected. ${ }^{38}$ Although glycocalyx damage occurs early in diabetic disease, the clinical manifestations of this damage may be significantly delayed and remain dependent on the function of the vascular bed studied.

\section{Diabetic Nephropathy}

The hallmark of diabetic nephropathy (DN) is microalbuminuria. In diabetes, uACR is a key screening test, predicting patients at the highest risk of progressive renal and vascular disease. ${ }^{39}$ Electron microscopy to study glomerular structural changes in patients with diabetes found that loss of endothelial fenestration area correlated with the UACR more strongly than podocyte detachment. ${ }^{40}$ These data suggest that endothelial damage is likely to be one of the key steps that results in albuminuria in diabetes. ${ }^{40}$ The authors of this study did not examine the glycocalyx, 
but it seems likely that the endothelial cell damage, resulting in fenestration loss, was the result of altered vascular endothelial growth factor (VEGF) signaling. ${ }^{41,42}$ Altered VEGF signaling results in glycocalyx loss. ${ }^{15,29,43}$ Given the evidence that supports the importance of the glycocalyx in glomerular filtration, it seems likely that glycocalyx damage contributed to the microalbuminuria seen in these patients.

Experimental evidence supports this view. On cultured monolayers of conditionally immortalized glomerular endothelial cells, high concentrations of glucose result in a marked reduction in the biosynthesis of the glycocalyx component HS, with an associated increase in albumin permeability. ${ }^{44}$ Jeansson et $\mathrm{al}^{45}$ confirmed that increased glomerular albumin leakage contributed to the albuminuria detected in animal models of diabetes by cooling isolated kidneys to $8^{\circ} \mathrm{C}$ to limit tubular effects. Loss of HA and HS from the glomerular capillary wall has been confirmed in streptozocin-induced diabetic rats and Zucker fatty rats, suggesting that glycocalyx damage is likely to contribute to the increase in albumin filtration seen in these disease models. ${ }^{46,47}$ More recently, it is reported that diabetic glomerular glycocalyx damage can be prevented in the mouse streptozocin model of diabetes by administering a matrix metalloprotease (MMP) 2/9 inhibitor. ${ }^{48}$ A daily injection of MMP2/9 inhibitor reduced syndecan 4 loss from the glycocalyx and significantly reduced albuminuria by reducing glomerular albumin permeability. ${ }^{48}$ As previously reported, high-power electron microscopy images of the GFB and glomerular endothelial glycocalyx suggested that glycocalyx changes had occurred before other significant changes to the GFB ${ }^{29,35,48}$ An isolated glomerular albumin permeability assay used early in the diabetic disease course confirmed that glomerular glycocalyx loss is associated with increased glomerular albumin permeability in both the mouse and rat streptozocin diabetic models. ${ }^{29,48}$ This unique assay has the advantage of studying glomerular permeability in the absence of hemodynamic influence, ensuring that alterations in the glomerular perfusion pressure will not influence permeability measurements. In addition, this assay allows us to study changes in glomerular permeability in isolation from the renal tubules and hence confounding tubular albumin reuptake. This assay found that glomerular albumin leakage may be significantly increased before an increase in uACR is detectable. In summary, the current evidence suggests that glycocalyx injury is likely to contribute to the early pathogenesis of DN.

\section{Diabetic Retinopathy}

Diabetic retinopathy (DR), like DN, is a manifestation of diabetic microvascular damage. The retina is a continuation of the central nervous system with a blood retina barrier. The pathogenesis of DR has been reviewed in detail elsewhere, ${ }^{49,50}$ but the role of the retinal endothelial glycocalyx and its impairment in diabetes is an area of ongoing research. DR is characterized by microaneurysms, leukocyte-endothelial adhesion, hemorrhage, capillary occlusion, neovascularization, and increased permeability. ${ }^{51}$ Diabetic rats have a significantly thinner retinal endothelial glycocalyx compared with control rats (28.3 versus 60.2 $\mathrm{nmol} / \mathrm{L}, P<0.01$ ), measured using transmission electron microscopy. ${ }^{52}$ In addition, in the Akita mouse model of type 1 diabetes, anesthetized diabetic mice have a significantly thinner glycocalyx in retinal arterioles. ${ }^{51}$ In human volunteers, combined fluorescein and indocyanine green angiography also demonstrated a significantly thinner glycocalyx in patients with type 2 diabetes compared with healthy controls. ${ }^{53}$ In the same study, the authors measured the rate at which ${ }^{125}$ I-labeled albumin left the plasma, confirming an increased rate of loss in patients with diabetes, which is consistent with an increase in systemic albumin permeability. ${ }^{53}$ In streptozocin-induced diabetic rats, retinal permeability was also increased (measured by fluorescein isothiocyanate-dextran accumulation in retinal tissue). ${ }^{54}$ In the same study, overexpression of endomucin prevented damage to the endothelial glycocalyx, reduced leukocyte adhesion, and reduced retinal vessel permeability. ${ }^{54} \mathrm{~A}$ reduction in tight junctions within the interendothelial cleft of retinal vessels has also been reported early in diabetic disease, making the direct contribution of glycocalyx injury impossible to assess. ${ }^{54,55}$ However, it seems likely that glycocalyx injury is contributing to the pathogenesis of DR through direct increases in permeability and by facilitating leukocyte adhesion; glycocalyx preservation therefore remains a promising therapeutic option. ${ }^{54}$

\section{Sepsis}

During sepsis, the endothelial glycocalyx becomes thinner and the cover sparser, contributing to tissue edema. ${ }^{56,57}$ In mice, intravenous lipopolysaccharide injection results in activation of the innate immune system, shock, lactic acidosis, myocardial impairment, and increased levels of circulating tumor necrosis factor- $\alpha$ and IL- $6 .{ }^{58}$ After lipopolysaccharide administration, mice have significantly thinner aortic glycocalyx compared with controls. ${ }^{59}$ Elevated levels of tumor necrosis factor- $\alpha$ are likely to contribute to glycocalyx damage in this model via increased MMP activity and syndecan loss. ${ }^{60}$ In human volunteers, a low-dose endotoxin model resulted in a significant reduction in the depth of the sublingual vessel glycocalyx (measured using side stream imaging) and a concurrent elevation in plasma HA, suggesting glycocalyx shedding. ${ }^{61}$ Multiple circulating biomarkers of glycocalyx shedding have been studied in humans as markers of sepsis, including syndecan 1, HS, and HA. ${ }^{56,62,63}$ It is hoped that in the future these targets may provide practitioners with additional diagnostic and prognostic information. In sepsis, circulating sheddases, including A disintegrin and metalloproteinase 15, heparanase, and MMP2/9, have been implicated in the degradation of the glycocalyx. ${ }^{63-66}$ It seems likely therefore that the albuminuria observed in sepsis, at least in part, results from 
glycocalyx injury and increased glomerular albumin permeability. ${ }^{14,67-69}$

Increased pulmonary vascular permeability in sepsis manifests as acute lung injury and acute respiratory distress syndrome, which can occur early in sepsis. ${ }^{70}$ However, the evidence to date suggests that evidence should not be extrapolated, supporting peripheral glycocalyx damage mediating increased vasculature permeability, to the pulmonary vasculature in sepsis. Mouse pulmonary endothelial glycocalyx appears to be substantially thicker than that seen in the mouse systemic vessels (cremaster muscle). ${ }^{71}$ Conflicting evidence exists supporting the role of the pulmonary vessel glycocalyx as a permeability barrier. Although a study using bovine lung microvasculature endothelial cells in vitro suggested that HS within the glycocalyx contributed to cell barrier function, a study using ex vivo rat lungs did not. ${ }^{72,73}$ In addition, in isolated mouse lungs perfused with $4 \%$ Evans blue-labeled albumin, neither water nor albumin permeability was measurably altered by glycocalyx degradation. In vivo heparinase III enzyme infusion did not result in detectable pulmonary edema in mice. ${ }^{74}$ These findings could be explained by the double barrier hypothesis (Figure 3). Glycocalyx injury in isolation may not result in measurable increases in pulmonary permeability to macromolecules in the presence of an intact second barrier (the endothelial monolayer). However, by altering the level of immune cell extravazation and inflammation, the pulmonary glycocalyx may still have a key role in maintaining pulmonary homeostasis. $^{74}$

The endothelial cells within the cerebral circulation form part of the blood brain barrier, limiting transcytosis and solute diffusion. ${ }^{75}$ The glycocalyx forms the most luminal layer of the blood brain barrier. Although cytokines smaller than $40 \mathrm{kDa}$ are likely to freely cross the glycocalyx, the passage of larger molecules and interactions between circulating cells and the endothelium are restricted by an intact glycocalyx. ${ }^{75,76}$ Groups are currently working to investigate the function and structure of the cerebral glycocalyx. ${ }^{76,77}$ In vivo imaging in mice suggests that the cerebral arteries and capillaries have an intact glycocalyx, whereas veins and venules do not. ${ }^{76}$ As yet, it is not known if the same distribution will be seen in the human cerebral circulation. During sepsis, patients commonly develop cognitive impairment (acute delirium). The pathogenesis of this condition is complex, with evidence to date suggesting a role for cytokines (IL-1, IL- 6 , and tumor necrosis factor- $\alpha$ ) penetrating the blood brain barrier and activating astrocytes. ${ }^{78}$ Studies now suggest that during sepsis HS fragments penetrate the hippocampal blood brain barrier to inhibit long-term potentiation-the process responsible for memory formation. ${ }^{34,79}$ The blood brain barrier of the hippocampal region appears to be susceptible to damage, with an apparent predisposition to age-related vascular dysfunction. ${ }^{80}$ It seems possible in sepsis, therefore, that an increase in the permeability of the blood brain barrier of the hippocampus to HS fragments, possibly as a direct result of sepsis-induced glycocalyx shedding, contributes to the hippocampal HS fragment accumilation. ${ }^{34}$ Interestingly, a limited clinical study using side-stream dark field imaging found that the glycocalyx depth varies between cortical and hippocampal microvessels. ${ }^{77}$ The hippocampal endothelial glycocalyx was thicker than the cortical endothelial glycocalyx, suggesting that structural differences in the glycocalyx at the two sites may exit. ${ }^{77}$ Further work is needed to determine whether the hippocampal microvascular glycocalyx is predisposed to damage during sepsis because this could represent an exciting therapeutic target in the future to limit the comorbidity associated with sepsis.

\section{Preeclampsia}

Preeclampsia is a complication that affects $3 \%$ to $5 \%$ of pregnancies. The hallmark of the condition is endothelial cell damage, leading to altered microvascular permeability. ${ }^{81,82}$ Endothelial glycocalyx dysfunction may contribute to this. Activation and dysfunction of the maternal endothelium in preeclampsia is mediated (in part) through the release of placentally derived factors. ${ }^{83}$ Hypoxic trophoblasts release antiangiogenic cytokines, including soluble fms-like tyrosine kinase 1 into the maternal circulation. In addition, there is a reduction in the proangiogenic placental growth factor, a member of the VEGF family. ${ }^{84}$ The resulting imbalance contributes to the altered vascular permeability seen in preeclampsia. ${ }^{85}$ Historically, VEGF-A, VEGF-C, and VEGF- $\mathrm{A}_{165} \mathrm{~b}$ have altered the endothelial glycocalyx. ${ }^{15,43}$ Interestingly, a failure in first trimester upregulation of VEGF- $\mathrm{A}_{165} \mathrm{~b}$ is predictive of the development of preeclampsia. ${ }^{86}$ The important link among VEGF, permeability, and the endothelial glycocalyx is an increasing focus in PE research.

The net effect of PE is glycocalyx degradation, illustrated by an increased perfused boundary region in sublingual capillaries, assessed by side stream imaging in patients with early-onset preeclampsia. ${ }^{87}$ However the mechanism of damage remains unclear because of conflicting data to date. Both HS and HA are elevated in early-onset preeclampsia (onset before 34 weeks), severe preeclampsia, and the related syndrome of hemolysis, elevated liver enzyme levels, and low platelet counts. ${ }^{87-89}$ However, although soluble syndecan-1 increases with advancing gestation in normal pregnancy and preeclampsia, its utility as a marker of preeclampsia remains unclear. ${ }^{87,90,91}$ The sample size, diagnostic criteria, and different preeclampsia subtypes may explain the discrepancies observed. Recently developed electron microscopy-based methods have reliably measured the glycocalyx depth in the fetal and maternal circulation of human placental tissue to aid future work in this area. ${ }^{92}$

\section{Atherosclerosis}

The major focus of this review has been on the function of the endothelial glycocalyx within the microvasculature. 
However, there is now an emerging field of research on the role of the glycocalyx in the prevention of atherosclerosis in larger blood vessels. Atherosclerosis is a chronic arterial vascular disease that results from lipid-filled plaque accumulation. ${ }^{93}$ The subsequent erosion or rupture of plaques can result in acute arterial occlusion, myocardial infarction, or cerebrovascular accident. Damage to the endothelial glycocalyx has been linked to the pathogenesis of atheroma through multiple pathways, which have recently been reviewed by Mitra et al, ${ }^{93}$ but alterations in transendothelial permeability appear to be a key step. Atheroma tends to form in areas of nonlaminar blood flow, adjacent to bends or branch points. ${ }^{93,94}$ In vitro, nonuniform fluid flow rapidly results in reduced glycocalyx expression of HS and sialic acids, with an associated reduction in glycocalyx thickness and coverage. ${ }^{93}$ Areas of glycocalyx damage correlated with oxidized low-density lipoprotein cholesterol uptake. ${ }^{93}$ In vivo, lipid accumulation in apolipoprotein $\mathrm{E}$-deficient (ApoE-/-) mice increases in areas of endothelium with incomplete glycocalyx coverage ( $71 \%$ glycocalyx coverage in regions of plaque versus $97 \%$ coverage in plaque-free regions). ${ }^{95}$ Low-density lipoprotein cholesterol uptake is considered important because it triggers CD40/CD40 ligand signaling pathways, and subsequent macrophage uptake and degradation of oxidized low-density lipoprotein results in their transformation into foam cells, a key finding on histologic examination of plaques. ${ }^{96}$

\section{Conclusions}

Further research into the structural variability of the glycocalyx and the contribution of the endothelial glycocalyx to vessel wall permeability is needed. This research needs to be targeted to both the organ and vessel of interest. The glycocalyx is a highly specialized structure, and pathologic states should not be expected to affect remote vascular beds or the different vessels within them in the same way. Highly sensitive tools, such as the ex vivo glomerular permeability assay, are providing new evidence that glycocalyx injury in early disease models has functional consequences and should not be ignored. Glycocalyx damage is associated with increased vessel wall permeability in multiple clinical conditions and has massive potential medical relevance. Restoring or maintaining the glycocalyx represents an inviting therapeutic strategy, but for the full potential of this strategy to be realized, an increased understanding of how the glycocalyx structure responds to disease and the functional consequences of glycocalyx damage is needed.

\section{References}

1. Betteridge KB, Arkill KP, Neal CR, Harper SJ, Foster RR, Satchell SC, Bates DO, Salmon AHJ: Sialic acids regulate microvessel permeability, revealed by novel in vivo studies of endothelial glycocalyx structure and function. J Physiol 2017, 595:5015-5035
2. Butler MJ, Ramnath R, Kadoya H, Desposito D, Riquier-Brison A, Ferguson JK, Onions KL, Ogier AS, ElHegni H, Coward RJ, Welsh GI, Foster RR, Peti-Peterdi J, Satchell SC: Aldosterone induces albuminuria via matrix metalloproteinase-dependent damage of the endothelial glycocalyx. Kidney Int 2019, 95:94-107

3. Dane MJ, van den Berg BM, Lee DH, Boels MG, Tiemeier GL, Avramut MC, van Zonneveld AJ, van der Vlag J, Vink $\mathrm{H}$, Rabelink TJ: A microscopic view on the renal endothelial glycocalyx. Am J Physiol Renal Physiol 2015, 308:F956-F966

4. Singh A, Satchell SC, Neal CR, McKenzie EA, Tooke JE, Mathieson PW: Glomerular endothelial glycocalyx constitutes a barrier to protein permeability. J Am Soc Nephrol 2007, 18: 2885-2893

5. Curry FR: Microvascular solute and water transport. Microcirculation 2005, 12:17-31

6. Curry FE: Layer upon layer: the functional consequences of disrupting the glycocalyx-endothelial barrier in vivo and in vitro. Cardiovasc Res 2017, 113:559-561

7. Curry FE, Michel CC: The endothelial glycocalyx: barrier functions versus red cell hemodynamics: a model of steady state ultrafiltration through a bi-layer formed by a porous outer layer and more selective membrane-associated inner layer. Biorheology 2019, 56:113-130

8. Potter DR, Damiano ER: The hydrodynamically relevant endothelial cell glycocalyx observed in vivo is absent in vitro. Circ Res 2008, 102:770-776

9. Chappell D, Jacob M, Paul O, Rehm M, Welsch U, Stoeckelhuber M, Conzen P, Becker BF: The glycocalyx of the human umbilical vein endothelial cell: an impressive structure ex vivo but not in culture. Circ Res 2009, 104:1313-1317

10. Edwards A, Daniels BS, Deen WM: Ultrastructural model for size selectivity in glomerular filtration. Am J Physiol 1999, 276: F892-F902

11. Punyaratabandhu N, Kongoup $P$, Dechadilok $P$, Katavetin $P$, Triampo W: Transport of spherical particles through fibrous media and a row of parallel cylinders: applications to glomerular filtration. J Biomech Eng 2017, 139:121005

12. Satchell S: The role of the glomerular endothelium in albumin handling. Nat Rev Nephrol 2013, 9:717-725

13. Weinbaum S, Tarbell JM, Damiano ER: The structure and function of the endothelial glycocalyx layer. Annu Rev Biomed Eng 2007, 9: 121-167

14. Salmon AH, Satchell SC: Endothelial glycocalyx dysfunction in disease: albuminuria and increased microvascular permeability. J Pathol 2012, 226:562-574

15. Oltean S, Qiu Y, Ferguson JK, Stevens M, Neal C, Russell A, Kaura A, Arkill KP, Harris K, Symonds C, Lacey K, Wijeyaratne L, Gammons M, Wylie E, Hulse RP, Alsop C, Cope G, Damodaran G, Betteridge KB, Ramnath R, Satchell SC, Foster RR, BallmerHofer K, Donaldson LF, Barratt J, Baelde HJ, Harper SJ, Bates DO, Salmon AH: Vascular endothelial growth factor-A165b is protective and restores endothelial glycocalyx in diabetic nephropathy. J Am Soc Nephrol 2015, 26:1889-1904

16. Eremina V, Jefferson JA, Kowalewska J, Hochster H, Haas M, Weisstuch J, Richardson C, Kopp JB, Kabir MG, Backx PH, Gerber HP, Ferrara N, Barisoni L, Alpers CE, Quaggin SE: VEGF inhibition and renal thrombotic microangiopathy. N Engl J Med 2008, 358:1129-1136

17. Dimke H, Maezawa Y, Quaggin SE: Crosstalk in glomerular injury and repair. Curr Opin Nephrol Hypertens 2015, 24:231-238

18. Dane MJ, van den Berg BM, Avramut MC, Faas FG, van der Vlag J, Rops AL, Ravelli RB, Koster BJ, van Zonneveld AJ, Vink H, Rabelink TJ: Glomerular endothelial surface layer acts as a barrier against albumin filtration. Am J Pathol 2013, 182:1532-1540

19. Lazzara MJ, Deen WM: Model of albumin reabsorption in the proximal tubule. Am J Physiol Renal Physiol 2007, 292:F430-F439

20. Norden AG, Scheinman SJ, Deschodt-Lanckman MM, Lapsley M, Nortier JL, Thakker RV, Unwin RJ, Wrong O: Tubular proteinuria 
defined by a study of Dent's (CLCN5 mutation) and other tubular diseases. Kidney Int 2000, 57:240-249

21. Gambaro G, Baggio B, Cicerello E, Mastrosimone S, Marzaro G, Borsatti A, Crepaldi G: Abnormal erythrocyte charge in diabetes mellitus: link with microalbuminuria. Diabetes 1988, 37:745-748

22. Ando Y, Okada H, Takemura G, Suzuki K, Takada C, Tomita H, Zaikokuji R, Hotta Y, Miyazaki N, Yano H, Muraki I, Kuroda A, Fukuda H, Kawasaki Y, Okamoto H, Kawaguchi T, Watanabe T, Doi T, Yoshida T, Ushikoshi H, Yoshida S, Ogura S: Brain-specific ultrastructure of capillary endothelial glycocalyx and its possible contribution for blood brain barrier. Sci Rep 2018, 8:17523

23. Rehm M, Zahler S, Lotsch M, Welsch U, Conzen P, Jacob M, Becker BF: Endothelial glycocalyx as an additional barrier determining extravasation of $6 \%$ hydroxyethyl starch or $5 \%$ albumin solutions in the coronary vascular bed. Anesthesiology 2004, 100: $1211-1223$

24. Rops AL, Gotte M, Baselmans MH, van den Hoven MJ, Steenbergen EJ, Lensen JF, Wijnhoven TJ, Cevikbas F, van den Heuvel LP, van Kuppevelt TH, Berden JH, van der Vlag J: Syndecan1 deficiency aggravates anti-glomerular basement membrane nephritis. Kidney Int 2007, 72:1204-1215

25. Garsen M, Rops AL, Rabelink TJ, Berden JH, van der Vlag J: The role of heparanase and the endothelial glycocalyx in the development of proteinuria. Nephrol Dial Transplant 2014, 29:49-55

26. Earnshaw JS, Curtis CG, Powell GM, Dodgson KS, Olavesen AH, Gacesa P: The fate of intravenously administered highly purified bovine testicular hyaluronidase (Hyalosidase) in the rat. Biochem Pharmacol 1985, 34:2199-2203

27. Landsverk SA, Tsai AG, Cabrales P, Intaglietta M: Impact of enzymatic degradation of the endothelial glycocalyx on vascular permeability in an awake hamster model. Crit Care Res Pract 2012, 2012: 842545

28. Jeansson M, Haraldsson B: Glomerular size and charge selectivity in the mouse after exposure to glucosaminoglycan-degrading enzymes. J Am Soc Nephrol 2003, 14:1756-1765

29. Onions KL, Gamez M, Buckner NR, Baker SL, Betteridge KB, Desideri S, Dallyn BP, Ramnath RD, Neal CR, Farmer LK, Mathieson PW, Gnudi L, Alitalo K, Bates DO, Salmon AHJ, Welsh GI, Satchell SC, Foster RR: VEGFC reduces glomerular albumin permeability and protects against alterations in VEGF receptor expression in diabetic nephropathy. Diabetes 2019, 68:172-187

30. van den Berg BM, Wang G, Boels MGS, Avramut MC, Jansen E, Sol W, Lebrin F, Jan van Zonneveld A, de Koning EJP, Vink H, Grone HJ, Carmeliet P, van der Vlag J, Rabelink TJ: Glomerular function and structural integrity depend on hyaluronan synthesis by glomerular endothelium. J Am Soc Nephrol 2019, 30:1886-1897

31. Gil N, Goldberg R, Neuman T, Garsen M, Zcharia E, Rubinstein AM, van Kuppevelt T, Meirovitz A, Pisano C, Li JP, van der Vlag J, Vlodavsky I, Elkin M: Heparanase is essential for the development of diabetic nephropathy in mice. Diabetes 2012, 61:208-216

32. Jung O, Trapp-Stamborski V, Purushothaman A, Jin H, Wang H, Sanderson RD, Rapraeger AC: Heparanase-induced shedding of syndecan-1/CD138 in myeloma and endothelial cells activates VEGFR2 and an invasive phenotype: prevention by novel synstatins. Oncogenesis 2016, 5:e202

33. Kim EY, Roshanravan H, Dryer SE: Syndecan-4 ectodomain evokes mobilization of podocyte TRPC6 channels and their associated pathways: an essential role for integrin signaling. Biochim Biophys Acta 2015, 1853:2610-2620

34. Zhang X, Han X, Xia K, Xu Y, Yang Y, Oshima K, Haeger SM, Perez MJ, McMurtry SA, Hippensteel JA, Ford JA, Herson PS, Liu J, Schmidt EP, Linhardt RJ: Circulating heparin oligosaccharides rapidly target the hippocampus in sepsis, potentially impacting cognitive functions. Proc Natl Acad Sci U S A 2019, 116:9208-9213

35. Desideri S, Onions KL, Qiu Y, Ramnath RD, Butler MJ, Neal CR, King MLR, Salmon AE, Saleem MA, Welsh GI, Michel CC, Satchell SC, Salmon AHJ, Foster RR: A novel assay provides sensitive measurement of physiologically relevant changes in albumin permeability in isolated human and rodent glomeruli. Kidney Int 2018, 93:1086-1097

36. Nieuwdorp M, van Haeften TW, Gouverneur MC, Mooij HL, van Lieshout MH, Levi M, Meijers JC, Holleman F, Hoekstra JB, Vink H, Kastelein JJ, Stroes ES: Loss of endothelial glycocalyx during acute hyperglycemia coincides with endothelial dysfunction and coagulation activation in vivo. Diabetes 2006, 55:480-486

37. Lambadiari V, Pavlidis G, Kousathana F, Maratou E, Georgiou D, Andreadou I, Kountouri A, Varoudi M, Balampanis K, Parissis J, Triantafyllidi H, Katogiannis K, Birba D, Lekakis J, Dimitriadis G, Ikonomidis I: Effects of different antidiabetic medications on endothelial glycocalyx, myocardial function, and vascular function in type 2 diabetic patients: one year follow-up study. J Clin Med 2019, 8

38. Targosz-Korecka M, Jaglarz M, Malek-Zietek KE, Gregorius A, Zakrzewska A, Sitek B, Rajfur Z, Chlopicki S, Szymonski M: AFMbased detection of glycocalyx degradation and endothelial stiffening in the $\mathrm{db} / \mathrm{db}$ mouse model of diabetes. Sci Rep 2017, 7:15951

39. Satchell SC, Tooke JE: What is the mechanism of microalbuminuria in diabetes: a role for the glomerular endothelium? Diabetologia 2008, 51:714-725

40. Toyoda M, Najafian B, Kim Y, Caramori ML, Mauer M: Podocyte detachment and reduced glomerular capillary endothelial fenestration in human type 1 diabetic nephropathy. Diabetes 2007, 56:2155-2160

41. Tschulakow A, Christner S, Julien S, Ludinsky M, van der Giet M, Schraermeyer U: Effects of a single intravitreal injection of aflibercept and ranibizumab on glomeruli of monkeys. PLoS One 2014, 9:e113701

42. Eleftheriadis T, Antoniadi G, Pissas G, Liakopoulos V, Stefanidis I: The renal endothelium in diabetic nephropathy. Ren Fail 2013, 35: 592-599

43. Foster RR, Armstrong L, Baker S, Wong DW, Wylie EC, Ramnath R, Jenkins R, Singh A, Steadman R, Welsh GI, Mathieson PW, Satchell SC: Glycosaminoglycan regulation by VEGFA and VEGFC of the glomerular microvascular endothelial cell glycocalyx in vitro. Am J Pathol 2013, 183:604-616

44. Singh A, Friden V, Dasgupta I, Foster RR, Welsh GI, Tooke JE, Haraldsson B, Mathieson PW, Satchell SC: High glucose causes dysfunction of the human glomerular endothelial glycocalyx. Am J Physiol Renal Physiol 2011, 300:F40-F48

45. Jeansson M, Granqvist AB, Nystrom JS, Haraldsson B: Functional and molecular alterations of the glomerular barrier in long-term diabetes in mice. Diabetologia 2006, 49:2200-2209

46. Satoh M, Kobayashi S, Kuwabara A, Tomita N, Sasaki T, Kashihara N: In vivo visualization of glomerular microcirculation and hyperfiltration in streptozotocin-induced diabetic rats. Microcirculation 2010, 17:103-112

47. Kuwabara A, Satoh M, Tomita N, Sasaki T, Kashihara N: Deterioration of glomerular endothelial surface layer induced by oxidative stress is implicated in altered permeability of macromolecules in Zucker fatty rats. Diabetologia 2010, 53:2056-2065

48. Ramnath RD, Butler MJ, Newman G, Desideri S, Russell A, Lay AC, Neal CR, Qiu Y, Fawaz S, Onions K, Gamez M, Crompton M, Michie C, Finch N, Coward RJ, Welsh GI, Foster RR, Satchell SC: Blocking matrix metalloproteinase-mediated syndecan-4 shedding restores the endothelial glycocalyx and glomerular filtration barrier function in early diabetic kidney disease. Kidney Int 2019, [Epub ahead of print] doi:10.1016/j.kint.2019.09.035

49. Kowluru RA, Mishra M: Regulation of matrix metalloproteinase in the pathogenesis of diabetic retinopathy. Prog Mol Biol Transl Sci 2017, 148:67-85

50. Wong TY, Cheung CM, Larsen M, Sharma S, Simo R: Diabetic retinopathy. Nat Rev Dis Primers 2016, 2:16012

51. Leskova W, Pickett H, Eshaq RS, Shrestha B, Pattillo CB, Harris NR: Effect of diabetes and hyaluronidase on the retinal endothelial glycocalyx in mice. Exp Eye Res 2019, 179:125-131 
52. Kumase F, Morizane Y, Mohri S, Takasu I, Ohtsuka A, Ohtsuki H: Glycocalyx degradation in retinal and choroidal capillary endothelium in rats with diabetes and hypertension. Acta Med Okayama 2010, 64:277-283

53. Broekhuizen LN, Lemkes BA, Mooij HL, Meuwese MC, Verberne H, Holleman F, Schlingemann RO, Nieuwdorp M, Stroes ES, Vink H: Effect of sulodexide on endothelial glycocalyx and vascular permeability in patients with type 2 diabetes mellitus. Diabetologia 2010, 53:2646-2655

54. Niu T, Zhao M, Jiang Y, Xing X, Shi X, Cheng L, Jin H, Liu K: Endomucin restores depleted endothelial glycocalyx in the retinas of streptozotocin-induced diabetic rats. FASEB J 2019, 33: $13346-13357$

55. Wallow IH, Engerman RL: Permeability and patency of retinal blood vessels in experimental diabetes. Invest Ophthalmol Vis Sci 1977, 16: $447-461$

56. Uchimido R, Schmidt EP, Shapiro NI: The glycocalyx: a novel diagnostic and therapeutic target in sepsis. Crit Care 2019, 23:16

57. Chelazzi C, Villa G, Mancinelli P, De Gaudio AR, Adembri C: Glycocalyx and sepsis-induced alterations in vascular permeability. Crit Care 2015, 19:26

58. Fink MP: Animal models of sepsis. Virulence 2014, 5:143-153

59. Wiesinger A, Peters W, Chappell D, Kentrup D, Reuter S, Pavenstadt H, Oberleithner H, Kumpers P: Nanomechanics of the endothelial glycocalyx in experimental sepsis. PLoS One 2013, 8: e80905

60. Ramnath R, Foster RR, Qiu Y, Cope G, Butler MJ, Salmon AH, Mathieson PW, Coward RJ, Welsh GI, Satchell SC: Matrix metalloproteinase 9-mediated shedding of syndecan 4 in response to tumor necrosis factor alpha: a contributor to endothelial cell glycocalyx dysfunction. FASEB J 2014, 28:4686-4699

61. Nieuwdorp M, Meuwese MC, Mooij HL, van Lieshout MH, Hayden A, Levi M, Meijers JC, Ince C, Kastelein JJ, Vink H, Stroes ES: Tumor necrosis factor-alpha inhibition protects against endotoxin-induced endothelial glycocalyx perturbation. Atherosclerosis 2009, 202:296-303

62. Steppan J, Hofer S, Funke B, Brenner T, Henrich M, Martin E, Weitz J, Hofmann U, Weigand MA: Sepsis and major abdominal surgery lead to flaking of the endothelial glycocalix. J Surg Res 2011, 165:136-141

63. Becker BF, Jacob M, Leipert S, Salmon AH, Chappell D: Degradation of the endothelial glycocalyx in clinical settings: searching for the sheddases. Br J Clin Pharmacol 2015, 80:389-402

64. Yang X, Meegan JE, Jannaway M, Coleman DC, Yuan SY: A disintegrin and metalloproteinase 15-mediated glycocalyx shedding contributes to vascular leakage during inflammation. Cardiovasc Res 2018, 114:1752-1763

65. Lygizos MI, Yang Y, Altmann CJ, Okamura K, Hernando AA, Perez MJ, Smith LP, Koyanagi DE, Gandjeva A, Bhargava R, Tuder RM, Faubel S, Schmidt EP: Heparanase mediates renal dysfunction during early sepsis in mice. Physiol Rep 2013, 1:e00153

66. Cui N, Wang H, Long Y, Su L, Liu D: Dexamethasone suppressed LPS-induced matrix metalloproteinase and its effect on endothelial glycocalyx shedding. Mediators Inflamm 2015, 2015:912726

67. Adembri C, Sgambati E, Vitali L, Selmi V, Margheri M, Tani A, Bonaccini L, Nosi D, Caldini AL, Formigli L, De Gaudio AR: Sepsis induces albuminuria and alterations in the glomerular filtration barrier: a morphofunctional study in the rat. Crit Care 2011, 15:R277

68. Koike K, Aiboshi J, Shinozawa Y, Sekine K, Endo T, Yamamoto Y: Correlation of glomerular permeability, endothelial injury, and postoperative multiple organ dysfunction. Surg Today 2004, 34:811-816

69. De Gaudio AR, Adembri C, Grechi S, Novelli GP: Microalbuminuria as an early index of impairment of glomerular permeability in postoperative septic patients. Intensive Care Med 2000, 26:1364-1368

70. Matthay MA, Zemans RL, Zimmerman GA, Arabi YM, Beitler JR, Mercat A, Herridge M, Randolph AG, Calfee CS: Acute respiratory distress syndrome. Nat Rev Dis Primers 2019, 5:18
71. Schmidt EP, Yang Y, Janssen WJ, Gandjeva A, Perez MJ, Barthel L, Zemans RL, Bowman JC, Koyanagi DE, Yunt ZX, Smith LP, Cheng SS, Overdier KH, Thompson KR, Geraci MW, Douglas IS, Pearse DB, Tuder RM: The pulmonary endothelial glycocalyx regulates neutrophil adhesion and lung injury during experimental sepsis. Nat Med 2012, 18:1217-1223

72. Dull RO, Mecham I, McJames S: Heparan sulfates mediate pressureinduced increase in lung endothelial hydraulic conductivity via nitric oxide/reactive oxygen species. Am J Physiol Lung Cell Mol Physiol 2007, 292:L1452-L1458

73. Dull RO, Cluff M, Kingston J, Hill D, Chen H, Hoehne S, Malleske DT, Kaur R: Lung heparan sulfates modulate K(fc) during increased vascular pressure: evidence for glycocalyx-mediated mechanotransduction. Am J Physiol Lung Cell Mol Physiol 2012, 302:L816-L828

74. Yang Y, Schmidt EP: The endothelial glycocalyx: an important regulator of the pulmonary vascular barrier. Tissue Barriers 2013, 1

75. Galea I, Perry VH: The blood-brain interface: a culture change. Brain Behav Immun 2018, 68:11-16

76. Yoon JH, Lee ES, Jeong Y: In vivo imaging of the cerebral endothelial glycocalyx in mice. J Vasc Res 2017, 54:59-67

77. Haeren RHL, Rijkers K, Schijns O, Dings J, Hoogland G, van Zandvoort M, Vink H, van Overbeeke JJ: In vivo assessment of the human cerebral microcirculation and its glycocalyx: a technical report. J Neurosci Methods 2018, 303:114-125

78. Piva S, McCreadie VA, Latronico N: Neuroinflammation in sepsis: sepsis associated delirium. Cardiovasc Hematol Disord Drug Targets $2015,15: 10-18$

79. Hippensteel JA, Anderson BJ, Orfila JE, McMurtry SA, Dietz RM, Su G, Ford JA, Oshima K, Yang Y, Zhang F, Han X, Yu Y, Liu J, Linhardt RJ, Meyer NJ, Herson PS, Schmidt EP: Circulating heparan sulfate fragments mediate septic cognitive dysfunction. J Clin Invest 2019, 129:1779-1784

80. Montagne A, Barnes SR, Sweeney MD, Halliday MR, Sagare AP, Zhao Z, Toga AW, Jacobs RE, Liu CY, Amezcua L, Harrington MG, Chui HC, Law M, Zlokovic BV: Blood-brain barrier breakdown in the aging human hippocampus. Neuron 2015, 85:296-302

81. Boeldt DS, Bird IM: Vascular adaptation in pregnancy and endothelial dysfunction in preeclampsia. J Endocrinol 2017, 232: R27-R44

82. Tranquilli AL, Dekker G, Magee L, Roberts J, Sibai BM, Steyn W, Zeeman GG, Brown MA: The classification, diagnosis and management of the hypertensive disorders of pregnancy: a revised statement from the ISSHP. Pregnancy Hypertens 2014, 4:97-104

83. O'Brien M, Baczyk D, Kingdom JC: Endothelial dysfunction in severe preeclampsia is mediated by soluble factors, rather than extracellular vesicles. Sci Rep 2017, 7:5887

84. Levine RJ, Maynard SE, Qian C, Lim KH, England LJ, Yu KF, Schisterman EF, Thadhani R, Sachs BP, Epstein FH, Sibai BM, Sukhatme VP, Karumanchi SA: Circulating angiogenic factors and the risk of preeclampsia. N Eng1 J Med 2004, 350:672-683

85. Maynard SE, Min J-Y, Merchan J, Lim K-H, Li J, Mondal S, Libermann TA, Morgan JP, Sellke FW, Stillman IE, Epstein FH, Sukhatme VP, Karumanchi SA: Excess placental soluble fms-like tyrosine kinase 1 (sFlt1) may contribute to endothelial dysfunction, hypertension, and proteinuria in preeclampsia. J Clin Invest 2003, 111:649-658

86. Bills VL, Varet J, Millar A, Harper SJ, Soothill PW, Bates DO: Failure to up-regulate $\operatorname{VEGF(165)b~in~maternal~plasma~is~a~first~}$ trimester predictive marker for pre-eclampsia. Clin Sci (Lond) 2009, $116: 265-272$

87. Weissgerber TL, Garcia-Valencia O, Milic NM, Codsi E, Cubro H, Nath MC, White WM, Nath KA, Garovic VD: Early onset preeclampsia is associated with glycocalyx degradation and reduced microvascular perfusion. J Am Heart Assoc 2019, 8:e010647

88. Osmers RG, Schutz E, Diedrich F, Wehry B, Krauss T, Oellerich M, Kuhn W: Increased serum levels of hyaluronic acid in pregnancies 
complicated by preeclampsia or hemolysis, elevated liver enzymes, and low platelets syndrome. Am J Obstet Gynecol 1998, 178: $341-345$

89. Berg S, Engman A, Holmgren S, Lundahl T, Laurent TC: Increased plasma hyaluronan in severe pre-eclampsia and eclampsia. Scand J Clin Lab Invest 2001, 61:131-137

90. Hofmann-Kiefer KF, Knabl J, Martinoff N, Schiessl B, Conzen P, Rehm M, Becker BF, Chappell D: Increased serum concentrations of circulating glycocalyx components in HELLP syndrome compared to healthy pregnancy: an observational study. Reprod Sci 2013, 20: 318-325

91. Gandley RE, Althouse A, Jeyabalan A, Bregand-White JM, McGonigal S, Myerski AC, Gallaher M, Powers RW, Hubel CA: Low soluble syndecan-1 precedes preeclampsia. PLoS One 2016, 11 : e0157608
92. Fabre-Gray ACM, Down CJ, Neal CR, Foster RR, Satchell SC, Bills VL: Imaging the placental glycocalyx with transmission electron microscopy. Placenta 2018, 74:59-61

93. Mitra R, O'Neil GL, Harding IC, Cheng MJ, Mensah SA, Ebong EE: Glycocalyx in atherosclerosis-relevant endothelium function and as a therapeutic target. Curr Atheroscler Rep 2017, 19:63

94. Zand T, Majno G, Nunnari JJ, Hoffman AH, Savilonis BJ, MacWilliams B, Joris I: Lipid deposition and intimal stress and strain: a study in rats with aortic stenosis. Am J Pathol 1991, 139:101-113

95. Cancel LM, Ebong EE, Mensah S, Hirschberg C, Tarbell JM: Endothelial glycocalyx, apoptosis and inflammation in an atherosclerotic mouse model. Atherosclerosis 2016, 252:136-146

96. Parthasarathy S, Raghavamenon A, Garelnabi MO, Santanam N: Oxidized low-density lipoprotein. Methods Mol Biol 2010, 610: 403-417 